\title{
Planning workshop to develop a programme to investigate pollutant cause-effect relationships in cetaceans:
}

\section{'POLLUTION 2000+'}

\section{INTRODUCTION}

The meeting was held at CIDOB (Centre d'Informació i Documentació Internacionals a Barcelona), Barcelona, Spain, from 14-17 March 1999. Local arrangements for the meeting had been made by Aguilar and colleagues at the University of Barcelona and the Fundacio pel Desenvolupament Sostenible. Aguilar welcomed the participants to Barcelona. The list of participants is given as Annex A.

Donovan welcomed the participants on behalf of the IWC. He noted the Commission's increased interest in environmental matters concerning cetaceans, beginning in 1993 (IWC, 1994). The Scientific Committee had agreed to focus its consideration of such matters on two areas: pollution and environmental change. These were the subjects of two Workshops (IWC, 1997; Reijnders et al., 1999). As a result of these, research proposals to address important questions arising were being developed. A meeting had been held on the former (SOWER 2000) in Edinburgh earlier this month (IWC, 1999) and the present Workshop was to further develop an outline proposal (hereafter called POLLUTION 2000+) agreed by the Scientific Committee in 1997 (Aguilar et al., 1998).

\section{ARRANGEMENTS FOR THE MEETING}

Chairing of the meeting was shared by Aguilar, Donovan and Reijnders. Participants in the Workshop contributed various sections to the draft report. It was agreed that final editing of the report should be undertaken by the co-chairmen. The adopted Agenda is given as Annex B.

\section{OBJECTIVES OF THE PROGRAMME}

\subsection{Review of Aguilar et al. (1998)}

Donovan introduced Aguilar et al. (1998). It had been developed in order to further the main recommendation of the Bergen Workshop (Reijnders et al., 1999, p.22):

The Workshop believes that there are sufficient data on the adverse effects of pollutants on the health of other marine mammal and terrestrial species to warrant concern for cetaceans. However, the report and its recommendations show that a considerable amount of fundamental research is needed before it will be possible to adequately address the question of the effects of chemical pollutants on all cetaceans.

Notwithstanding the cautionary note that it is often not appropriate to extrapolate from one species to another, it is clear that if any progress is to be made within a reasonable timeframe, a multidisciplinary, multinational focused programme of research is required that concentrates on those species/arcas where 
there is most chance of success. The Scientific Committee (and the Commission) is strongly urged to consider ways to facilitate the development and execution of such research.

Three species are considered particularly suitable: the bottlenose dolphin; the harbour porpoise; and the white whale.

This outline proposal had been agreed by the Scientific Committee and the Commission in 1997 (IWC, 1998a; b). Subsequently, the proposal was strongly endorsed by ASCOBANS and the ICES Working Group on Marine Mammal Habitat. The latter group is developing a similar research proposal focusing on pinniped species, and has expressed a desire for scientific cooperation with the IWC and suggested exploration of possibilities for joint funding sources.

The present Workshop is a direct result of Aguilar et al. (1998) and its terms of reference are to develop and update the outline into a full field and analytical programme. In particular, Aguilar et al. (1998) recognised that while in

an ideal world, the ultimate objective of pollution studies for cetacean management is to determine a predictive model linking tissue pollutant levels with effects at the population level ... this is clearly not a realistic short-term goal but it might be achievable in the long-term'.

Given this, the proposal's primary aim was to attempt to:

'determine the relationship between levels in certain tissues and indicators of certain effects. It seemed appropriate to focus on two sets of pollutants: (1) that might provide information of more general applicability, e.g. impact of organochlorines; and (2) that are subject to more local interpretation such as impact of heavy metals.'

Aguilar et al. (1998) then outlined a programme to that aim, covering inter alia: sources of samples; associated biological information required; indicators to be examined; potential areas and species to be sampled; sample sizes and potential collaborators.

Aguilar et al. (1998) had highlighted potential populations to be studied: harbour porpoises, white whales and bottlenose dolphins (for organochlorines) and Amazon River dolphins (for heavy metals). Subsequent discussion with potential collaborators on the initially proposed project on the Amazon River dolphin has meant that this sub-project is now considered impractical. Thus, it was agreed at the present Workshop that the POLLUTION 2000+ programme should now focus solely on organochlorines (particularly PCBs - see Item 4.1).

During the present Workshop, it was agreed that some clarification of the objectives would be useful. The implication of setting a short-term goal, and the recognition of the Bergen Workshop that "a considerable amount of fundamental research is needed... 2 is that the IWC programme is the first stage in an ongoing, and necessarily iterative process. Stages in such a process include:

(1) examining the relationship between tissue levels and biomarkers;

(2) examining the relationship between biomarkers and effects;

(3) examining effects on individuals;

(4) examining how the effects on the individual affect population dynamics.

It was agreed that this first stage of the programme could proceed on two fronts: one, to examine a number of biomarkers (of exposure to and/or effect of PCBs) and try to determine whether a predictive and quantitative relationship with PCB levels in certain tissues exists; the other, to validate/calibrate sampling and analytical techniques to address such questions for cetaceans. Examination of the first requires relatively large sample sizes, and to the extent possible, control for known variables such as age, sex and reproductive condition. It does not require extremely detailed pathology at this stage (see Items 4.4 and 5.4). Examination of the 
second may require lower sample sizes but considerably more information. Two important sub-objectives are:

(1) determination of changes in concentrations of variables with post-mortem times;

(2) examination of relationships between concentrations of variables obtained from biopsy sampling with those of concentrations in other tissues that can only be obtained from fresh carcasses.

It is important to stress that the development of POLLUTION 2000+ should not be seen as suggesting that other research on pollutants and cetaceans is not of value. The IWC programme should be seen as a 'core' programme to address some fundamental questions of general applicability (it should be reiterated that the species and areas chosen were chosen because of the likelihood of success and not because of any specific conservation concerns for those species/areas). Its value is immeasurably enhanced by cooperation with existing programmes and as a context for the development of new programmes. The IWC should cooperate with other national and international bodies in a coordinating role (see Item 8). Certain research subjects that are considered of high relevance but that do not fit in the 'core' programme are identified here as 'auxiliary projects'. The IWC should encourage third parties to undertake these projects.

\section{IDENTIFICATION OF VARIABLES TO BE MEASURED}

\subsection{Pollutants}

Organochlorine compounds are considered the main focus of the present proposal because their origin is overwhelmingly anthropogenic, they are found at extremely high tissue concentrations in some populations of cetaceans, and they have recognised effects upon wildlife. Moreover, substantial background information exists on their patterns of variation, geographical distribution and tissue kinetics.

\subsection{Indicators}

\subsubsection{Sex hormones}

\subsubsection{REPRODLCTIVE SEASONALITY}

Interpretation of sex hormone levels requires knowledge of the natural cycle of hormones in the subject animals. For the bottlenose dolphin, information exists from studies of captive animals and live-recapture studies. This facilitates selection of time periods for sampling of reproductive hormone concentrations relative to contaminant body burdens. Selection of 'quiet periods' when hormonal activity is predictably at a minimum would reduce the kinds of individual variation that might be expected from measuring adults at different points of the reproductive cycle during the general breeding season. Bottlenose dolphin reproductive seasons typically last for several months, occurring during spring, summer and/or autumn (Wells and Scott, In press). However, this may not be a critical period for assessing PCB related hormonal effects. Females may ovulate repeatedly during a given season and males maintain enlarged testes and elevated levels of testosterone over the several month duration of the breeding season. Seasonality varies geographically; for example, dolphins inhabiting different sites in the southeastern USA may exhibit different patterns of seasonality, with the patterns remaining established over multiple generations and even when individuals are transferred to other locations (Urian et al., 1996).

Alternatively, it is possible in some cases to identify the reproductive status of bottlenose dolphins through observational studies. Identifiable dolphins can be monitored closely over time, and the timing of births can be used to identify reproductive status retrospectively. In 
some situations, it is possible to conduct hands-on examination and sampling of live dolphins. Such opportunities may allow blood sampling in conjunction with ultrasonic measurement of testis length and diameter, the ultrasonic identification of the presence or absence of a foetus, measurement of a foetus, or ultrasonic identification of a developing follicle to provide information on the reproductive status of individuals.

For the harbour porpoise and white whale, investigation of reproductive tract combined with possible blood analyses from freshly dead animals could facilitate the establishment of hormone profiles throughout the reproductive cycle. Information on basic reproductive biology of harbour porpoises is being obtained from captive animals in Kateminde, Denmark. This includes information on hormone profiles, behaviour, maturity status and different stages in reproductive status using ultrasound and cytology. Investigations of the male cycle are also being planned. The basic reproductive cycle (timing of reproduction, period of reproductive activity, duration of pregnancy) in harbour porpoise has been well documented from individuals taken in commercial fisheries (e.g. Read, 1990 and see Donovan and Bjørge, 1995). Similar data on white whales have been collected on animals taken in subsistence harvests (Braham, 1984; Marine Mammal Commission, 1999).

\subsubsection{Enzyme induction}

Organochlorines are known to induce metabolic enzymes (the cytochrome P450 isoenzyme system in some cases). Since the same system (hereafter called P450) is involved in the control of endogenous compounds such as steroid hormones, this induction may lead to disturbance in endocrine control. The induction of $\mathrm{P} 450$ systems by $\mathrm{PCBs}$ has been demonstrated in several marine mammal species. The P450 enzyme system is therefore a useful biomarker for exposure to inter alia PCBs.

\subsubsection{Thyroid hormones and vitamin A levels}

Organochlorines are known to produce alterations of both vitamin $\mathrm{A}$ and thyroid hormones, and so are potentially useful biomarkers. Thyroid hormones as well as vitamin A are inter alia involved in early development and also in immune function (Marine Mammal Commission, 1999; Reijnders, 1999).

\subsubsection{Indicators of immune system status}

\subsubsection{BLOOD CELL PARAMETERS}

A number of tests are available to measure immune function in humans and in domestic and laboratory animals. These tests include analysis of immune cells, lymphocyte stimulation tests, cytokine assays, antigen responses and lymphocyte proliferation. Some of these tests have been applied in marine mammals, but others still have to be developed. It is emphasised that a series of blood cell parameters should be used, as the individual tests usually relate to only one specific part of the immune system. Moreover, study of a wide spectrum of blood parameters may enable discrimination of the causes of perturbations, e.g. infection, physical trauma and those produced by toxins.

\subsubsection{IN VITRO TESTS (CELL, LINE CULTURES, MICROSOMES) - ALNILIARY PRO.JECT}

From recently harvested, beach cast or euthanised animals, tissues can be collected and maintained in tissue culture media or quickly frozen in tissue culture preservative for establishment of primary cultures and development of immortal cell lines. Establishment of 
cultures should allow in vitro metabolic and toxicity testing in the species of concern. These techniques are inexpensive alternatives to repeated capture or the maintaining of captive animals. However, one limitation of this approach is the difficulty in extrapolating to whole animal or population level effects. It will, however, provide mechanistic and metabolic information for specific species.

\section{2 .5 Porphlirins}

Porphyrins play a crucial role in the haem biosynthetic pathway. Disruplions of haem biosynthesis (usually referred to as porphyria) by contaminants has been found. Particularly liver porphyrins in wildlife differed markedly after exposure to PAHs. They are therefore good indicators of exposure to inter alia PCBs.

\subsubsection{DNA adducts (auxiliary project )}

The formation of DNA adducts may represent a good measure of the exposure of organisms to PAHs but not PCBs. Since the latter are the main focus of the proposal, DNA adducts are not considered as priority indicators in POLLUTION 2000+.

\subsubsection{Luciferase}

The proposed luciferase method (see Item 5.2.6) acts specifically via the Ah-receptor route and therefore is a biomarker of exposure to dioxin-type contaminants, as extracted from the tissue(s) of interest. This acts as a measure of dioxin-like exposure for the chemicals present, but not as a measure of the specific chemical basis.

\subsection{Biological variables}

\subsubsection{Body length, sex and age}

These are factors significantly affecting both the tissue concentration of organochlorine pollutants in cetaceans and their susceptibility to chemical insult (Aguilar et al., 1999). These variables are also critical for the assessment of reproductive condition, pathology and other variables relevant to the examination of pollutant impact on populations.

\subsubsection{Reproductive condition}

Reproductive condition affects some of the indicators to be measured (e.g. sex and other hormones). In some species it may also affect the food intake rate or the diet composition and, in this way, it influences nutritive condition. As PCBs are lipophilic, reproductive condition may therefore indirectly affect tissue levels of these compounds. Thus, determination of reproductive status is significant to assess both the observed indicators and the pollutant concentrations.

\subsubsection{Nutritive condition}

This is significant not only for the assessment of the health status of the individual examined but, because organochlorine compounds are highly lipophilic, changes in blubber layer thickness can have an effect on concentrations of, for example, PCBs in blubber, other organs and blood. Therefore, information on nutritive condition also enables interpretation of pollution concentrations found in tissues. 


\subsection{Pathology}

Detailed necropsies and clinical examinations are required to assess the overall health of an individual and to try to distinguish effects of contaminants from those caused by other known stressors. Pathological effects should help in the interpretation of bioindicator data in relation to contaminant levels.

\subsubsection{Developmental stability (auxiliary research)}

Also known as developmental homeostasis, this is an indication of the ability of the individual to develop its phenotypic characters. Within a given species, phenotypic heterogeneity among individuals may suggest disturbed development; in some marine mammals (from skull biometric studies), this has been associated with exposure to high levels of PCBs and other pollutants (Zakharov and Yablokov, 1990).

\section{ANALYTICAL TECHNIQUES}

\subsection{Pollutants}

\subsubsection{Coplanar PCBs}

Lipids are extracted from blubber using hexane as a solvent in a Soxhlet apparatus. A portion of this extract is mixed with sulphuric acid for the clean-up. Determination of organochlorine compounds is carried out using standard capillary GC-ECD (Gas Chromatography-Electron Capture Detection) techniques.

PCBs are extracted and cleaned-up from blubber samples by the method of alkalinealcohol digestion. The extract is run on a $5 \mathrm{~mm}$ i.d. column packed with $125 \mathrm{mg}$ of activated carbon to separate non-ortho coplanar PCB congeners from other PCB isomers. The hexane extract is successively cleaned with $10 \%$ fuming sulphuric acid and rinsed in distilled water. The analysis of non-ortho PCB congeners is carried out using a gas chromatograph with mass spectrometer (GC-MS) (Tanabe et al., 1987).

\subsection{Indicators}

\subsubsection{Sex hormone determination}

In plasma, serum and urine, sex hormone levels (oestradiol, progesterone, testosterone) can be directly assessed using RIA (Radio-immuno-assay). It may be possible to obtain information on levels from tissue samples by homogenisation in the presence of a solvent, liquid-liquid extraction, GPC (Gel Permeation Chromatography) and RIA with specific antibodies.

\subsubsection{Enzyme induction}

Concentration and/or enzymatic activity of some proteins are known to change with contaminant exposure. Proteins sensitive to PCB exposure include cytochrome P450 1A for planar PCBs, and P450 2B for some non-planar PCBs. P450 3A is also important for sex steroid metabolism.

P450 IA content can be measured in dermal endothelia, from all cetacean species examined to date, using monoclonal antibody 1-12-3 (Ronis et al., 1989) and other antibodies. A midline slice of epidermis and dermis from the skin/blubber biopsy core is fixed in formalin, and the protein expression measured immunohistochemically. Sections from any routine histology sample may also be stained.

P450 1 A, 2B and 3A can be measured for content and activity in liquid nitrogen frozen samples, by immunoblot and catalytic assay respectively. The catalytic assays are often fluorometric, such as for ethoxy-resorufin-O-deethylase (EROD). These are commonly referred to as Phase I enzymes. 


\subsubsection{Thyroid hormones and vitamin A}

Thyroxin (T4) and triiodothyronin (T3) are determined by standard radioimmunochemical methods.

Retinol analysis includes a saponification of the sample with an ethanolic $\mathrm{KOH}$ solution and a subsequent extraction with diethyl ether. The extract is analysed by HPLC (High Performance Liquid Chromatography fluoresence analysis) using a reversed phase C18 column. and an ultraviolet detector with a mobile phase of methanol/water.

\section{2.t Indirators of immune system status}

\subsubsection{BLOOD CELL PARAMETERS}

5.2.4.1.1 PHENOTYPIC ANALYSES

(1) White blood count - differential smear, total count.

(2) Red blood cell profile.

(3) Lymphocyte sub-populations: analytical flow cytometer and immunohistochemistry.

(4) Leukocyte adhesion proteins - analytical flow cytometry.

(5) Total Ig:

Quantitative: RID - Radial Immunodiffusion; ELISA (Enzyme-linked Immunosorbent Assays); Serum protein electrophoresis.

Qualitative: IEP - Immuno electrophoresis.

(6) Inflammatory cytokines: bioassay, ELISA - in development.

(7) Acute phase proteins: ELISA.

(8) Serum chemistries (complete).

\subsection{FUNCTIONAL ASSAYS}

(1) Lymphocyte blastogenesis (colorometric; radio-label).

(2) Lymphocyte activation (flow cytometry and $\mathrm{Ca}^{2+} / \mathrm{IL}-2$ receptor expression etc.).

\subsubsection{Porphyrins}

Usually porphyrinogenic effects are measured as the concentration of different porphyrins in liver, urine and blood samples. The measure is the ratio between different porphyrin-derivates.

\subsubsection{Luciferase}

There are Luciferase induction assays specific for dioxins/PCBs (DR-CALUX) and for (pseudo) oestrogens (ER-CALUX). Lipid extracts from e.g. bloodplasma, liver tissue, are processed over a sulphuric acid-silica column and the residue is added to the culture medium of CALUX cells. Following 24hr exposure, the CALUX cells are lysed and Luciferase activity (light production) is measured in a luminometer. This method directly gives total TEQs of dioxin-like activity/g of lipid (instead of GC-MS congener concentrations multiplied by TEF factors and summed up).

\subsection{Biological variables}

\subsubsection{Age, length and sex}

Body length will be measured as the distance (following a straight line but not the contour of the body) from the tip of the upper jaw to the notch between the flukes.

Sex will be determined either by direct examination of the external genitalia in dead or captured individuals or, in dolphins sampled at a distance with biopsy darts, by means of genetic analysis of skin. The skin will be preserved frozen or in DMSO and will be analysed 
by means of amplification by PCR of ZFX and ZFY, two specific sex chromosomal DNA regions which present slight differences in their nucleotide sequence (Palsboll et al., 1992).

Age determination will be carried out by counting growth layer groups in the dentine or the cementum of teeth. Teeth must be cleaned but not boiled, and fixed (see field protocol). In the laboratory they will be decalcified in Rapid Bone Decalcifier for the Preparation of Histological Materials (RDO), and longitudinally sectioned in a freezing microtome, stained with Hematoxylin, blued in weak ammonia solution, and mounted onto gelatin coated slides (Hohn and Lockyer, 1995).

\subsubsection{Reproductive condition}

\subsubsection{OBSERVATIONS}

Long-term monitoring of identified individuals can provide information on reproductive activity/condition. Female reproductive activity can be based on retrospective analysis of the timing of initial appearance of newbom and continued presence of a calf, or oestrus behaviour as indicated by social association patterns. It is possible to generate reproductive histories for identifiable females from some resident bottlenose dolphin populations.

\subsubsection{LIVE CAPTURE/RELEASE}

The following information on reproductive condition can be collected from live-caught animals:

(1) morphometric indications of maturation (length, girth, weight, allometrical differences);

(2) hormone (oestradiol, progesterone and testosterone) levels in blood, faeces, urine, saliva and other matrices as available;

(3) using ultrasound to determine maturity status, seasonal changes or pregnancy by measuring testes length and diameter, foetal presence and corpora lutea, especially valuable in conjunction with hormonal status;

(4) direct measurement or examination of external features (lactation, mammary development, semen in urine samples, ano-urogenital morphometrics).

\subsubsection{POST-MORTEM (AS ABOVE)}

(1) Gross, histologic and cytologic assessment of activity, maturity (spermatogenesis, follicle development, ovarian scars, uterine status) and pathology (see Item 5.4).

(2) Presence and orientation of foetus.

(3) Morphometrics of foetus and reproductive tract.

(4) Mammary development, presence of milk and histology.

\subsubsection{Nutritive condition}

Nutritive condition will be assessed using a combination of two types of measures: (1) morphometric data (body weight/length ratio, body perimeter at the level of the axillas and at the centre of the anus, thickness of the blubber in the mid body length at the mid point between the dorsal and ventral lines); and (2) total lipid content from at least a blubber sample collected from the dorsal region of the trunk, as determined by Soxhlet extraction of the tissue and subsequent gravimetry, as conducted in PCB analyses. In dead individuals, these measures and the blubber sample will be directly obtained from the corpse. In live-captured individuals, blubber thickness will be determined using ultrasound devices. In remotely biopsied individuals, assessment of nutritive condition will be carried out solely based on the lipid content analysis of the blubber sample (Aguilar and Borrell, 1990; Lockyer, 1995). 


\subsubsection{Stock identity/individual recognition}

Knowledge of stock identity may facilitate the interpretation of contaminant levels relative to exposure history for geographically-based stocks. A variety of tools are available for stock identification; the applicability of any one technique to a given situation varies with the species, and a suite of techniques is most likely to provide suitable information. In recent years, the advent of genetic techniques, particularly analyses of mtDNA, has proved to be a powerful additional tool, especially when used in combination with techniques such as morphometrics, individual identification, examination of parasite loads, contaminant profiles. stomach content analyses and stable isotope analyses.

Individual identification techniques (e.g. photographic identification or genetic fingerprinting) allow the monitoring of individuals over time, including the resampling of individuals throughout their life.

\subsection{Pathology}

\subsubsection{Gross pathology and histopathology of main organs (including dimensions)}

Such investigations (e.g. see Politi. 1994) are intended to try to assess general health status.

Gross necropsy starts with history and external examination (skin, orifices, mucosal membranes). At internal examination [organs marked * are to be weighed] liver*, kidney*, heart and lung are of particular toxicological interest. When focusing on the immune system, thymus*, spleen*, lymph nodes and bone marrow deserve attention; when the endocrine system is of concern, attention should be given to ovaries*, uterus (including foetus), testis*, adrenal*. thyroid* and pituitary. For specific investigations, additional tissues (eg. bone, skull) can be sampled (see below).

It is self-evident that sampling and examining additional tissues allows for more 'back-up' material available for future investigative studies.

The above mentioned organs must be sampled for histopathology, usually in buffered formalin.

\section{5.t.2 Health assessment of live animals}

In recent years, efforts have been undertaken to proactively assess the health of wild dolphin populations. A Workshop was held in 1993 to develop a means of translating clinical veterinary assessments of individual dolphins to population-level measures of health. A system was devised based on blood chemistry and haematology values obtained from samples collected during capture-release operations. A suite of 19 blood parameters considered to be important indicators of health and physiological processes was identified. These were weighted to take into account variations relative to age, sex, and reproductive condition where appropriate, and given a 'score'. The individual parameter scores are added together to provide a health score for the individual. The distribution of individual scores across the sampled population is examined to evaluate the general health condition of the population at any given time, relative to the Sarasota Bay, USA, reference population (Wells et al., 1995).

An initial testing study with dolphins from Sarasota Bay, FL, Matagorda Bay, TX, and Beaufort, NC, USA, suggested that it provides a relatively accurate representation of the health status of the dolphins, and health score patterns follow seasonal patterns of natural mortality in at least the Sarasota Bay dolphin community. Efforts to refine the system are ongoing. Other parameters under consideration for the model include weight, blubber depth, results of ultrasonic examinations, urine analysis, microbiological analyses and contaminant burdens. 
Consideration of a 'health score' as an indicator or biological variable in POLLUTION $2000+$ could provide additional insight into the effects of PCBs on these animals. The suite of blood parameters integrated by this model includes the basic indicators commonly used by veterinarians for diagnosing or monitoring a variety of health problems in individual cetaceans.

\subsubsection{Secondary sexual characteristics}

Routine length measurements should include snout to anus, and anus to posterior and anterior ends of the genital slit. The presence or absence of nipples and/or mammary slits should be recorded for males and females. Photographs should be taken wherever possible.

\section{SAMPLING (BY SPECIES, AREA AND VARIABLE)}

\subsection{Sampling location and target species}

An ideal scenario to investigate cause-effect relationships of pollutants in cetaceans would require the following elements:

(1) existence of a sample group inhabiting a pristine (or nearly pristine) environment that permits establishing patterns of variation (e.g. caused by sex, age or nutritive condition) in the proposed indicators in natural conditions;

(2) existence of a strong gradient (i.e. more than one order of magnitude) in exposure to pollutants, as measured by tissue concentrations, either between comparable segments of the same population or between comparable sample groups belonging to different populations of the same species;

(3) the ability to obtain a large enough sample size for each of the groups to be compared, to allow robust statistical analysis (preferably $n>30$ );

(4) field conditions permitting sampling of target tissues in order to allow optimum preservation conditions.

The information contained in Annex $\mathrm{C}$ indicates that there is not a single scenario that fulfils all these requirements. The Workshop therefore agreed that separate but complementary sub-projects should be carried out. These will focus on the objectives and groups of indicators for which the respective field conditions are most appropriate. The integration of the results of these sub-projects should provide a comprehensive insight and validate tools and methods that will provide the necessary background for the future phases of the research programme.

Table 1 details the advantages and limitations of each of the sub-projects proposed, and the objectives of the proposed studies.

There are a number of reasons for choosing biopsy-based studies of bottlenose dolphins. One of these is that if it can be shown that biopsy sampling can be used to monitor the 'health-pollutant' status, then this has great potential for future non-invasive monitoring. Another is that it will allow comparison of two 'pristine' areas and the results of this may have implications for interpreting data from different populations. Furthermore it will provide, in collaboration with the bottlenose dolphin live-capture sub-project, baseline information on certain indicators subject to a larger pollutant gradient, including pristine conditions.

The ability to collect large harbour porpoise sample sizes in the Icelandic/Danish and the northwest Atlantic fisheries (see Annex C) render them most useful for attempting to determine if a quantitative and predictive relationship exists between tissue levels and certain indicators. 


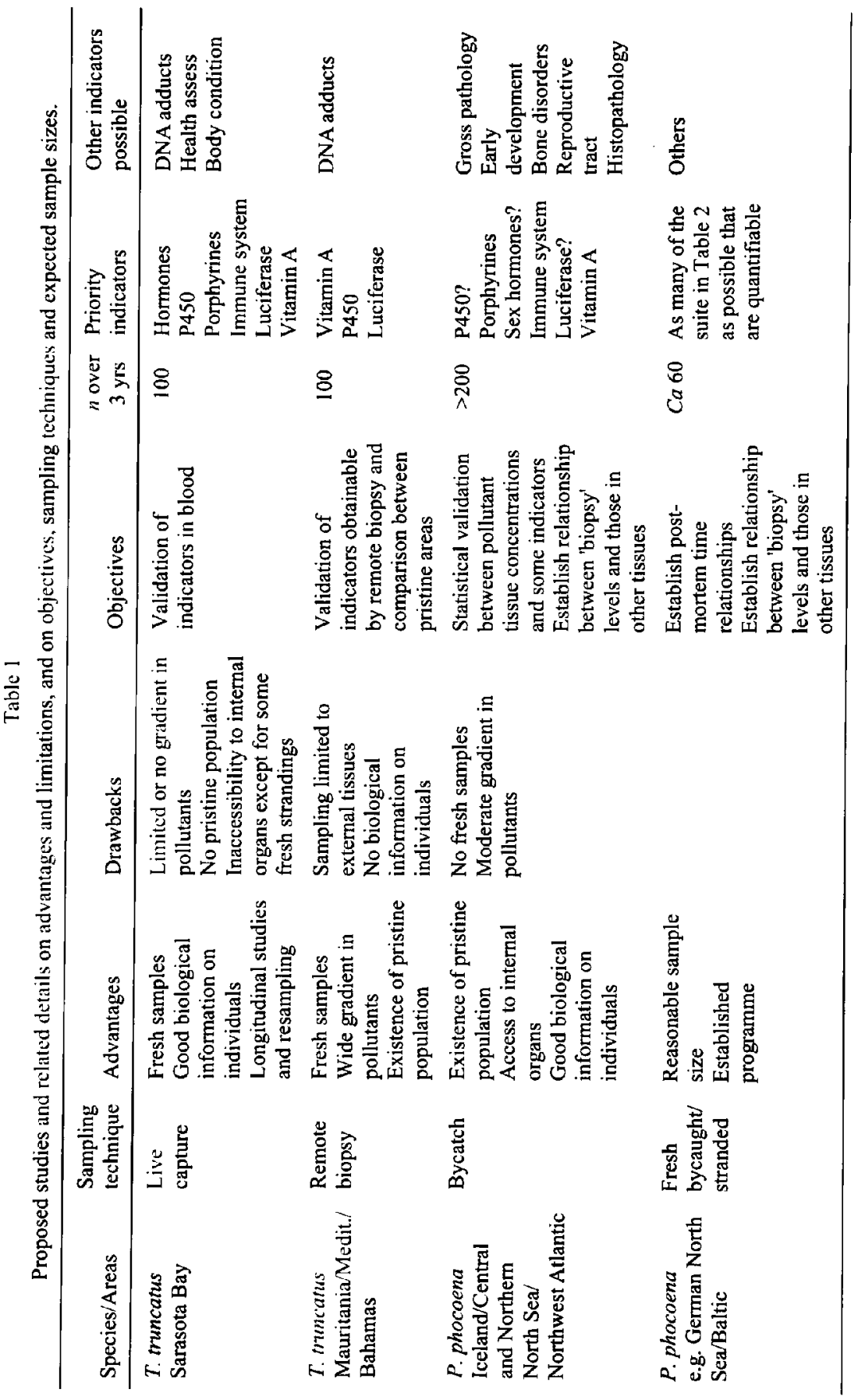


The objectives of relating post-mortem times with pollutant and indicator levels, and of relating levels in biopsy samples with those from other organs and tissues in the body, can be undertaken as part of the same sub-project. These questions can be addressed with smaller sample sizes.

Biopsy-based studies on white whales were also discussed. Due to the limited sample size obtainable for white whales from the St Lawrence Estuary, the inability to establish a significant gradient of tissue concentrations from Arctic whale stocks and the duplication of information acquired in the bottlenose dolphin studies, it was decided not to include the white whales as a study species in the POLLUTION 2000+ programme. However, it should be noted that this does not imply that pollutant studies on white whales are not important or may not be included in future phases of this iterative project.

\subsection{Sample quality and preservation methods}

The locations selected for the study provide opportunities for sampling using three different means: necropsy of dead animals (either harvested, bycaught in a fishing operation, euthanised or freshly stranded); biopsies obtained from live-captured individuals; and remote biopsies taken from free-ranging individuals. Table 2 details the tissues that can be obtained using each of these techniques.

The condition of the tissues thus obtained is variable and this opportunity allows us to compare 'condition' effects on the variables measured. While remote biopsies and live captures produce fresh tissues, post-mortem times in necropsies vary up to a few days. Some indicators are sensitive to prolonged post-mortem times and this limits their applicability in non-fresh samples. It was agreed that any animal to be sampled for the study should be less than 24 hours post-mortem and the time of sample preservation should also be noted. Table 2 depicts which indicators are likely to provide reliable results in fresh samples (less than 3 hours post-mortem) and in those moderately fresh (between 3 and 24 hours post-mortem).

Table 2 also details optimum conditions for storage, either for short-term periods (few months), long-term storage (few years) or archival purposes ( $>10$ years). Archival of non-used tissues or replicates is important to allow application in the future of more sensible or more reliable techniques that are now under development, or to investigate pollutants or indicators currently not considered.

\section{RESPONSIBLE LABORATORIES}

\subsection{Sample collection}

The agreed sub-projects are listed in Table 1. The Workshop is not in a position to finalise details of field collection but nominated the following people who would be responsible for coordinating/obtaining the necessary information required by the Steering Group (see Item 8 below).

(1) Bottlenose dolphin: Sarasota Bay - R. Wells.

(2) Bottlenose dolphin: Mauritania/Mediterranean - A. Aguilar.

(3) Bottlenose dolphin: Bahamas - P. Hammond.

(4) Harbour porpoise: Iceland - G.A. Vikingsson.

(5) Harbour porpoise: Central North Sea - F. Larsen.

(6) Harbour porpoise: Northern North Sea - A. Bjorge.

(7) Harbour porpoise: Northwest Atlantic - T. Rowles.

(8) Harbour porpoise: German North Sea/Baltic - U. Siebert. 


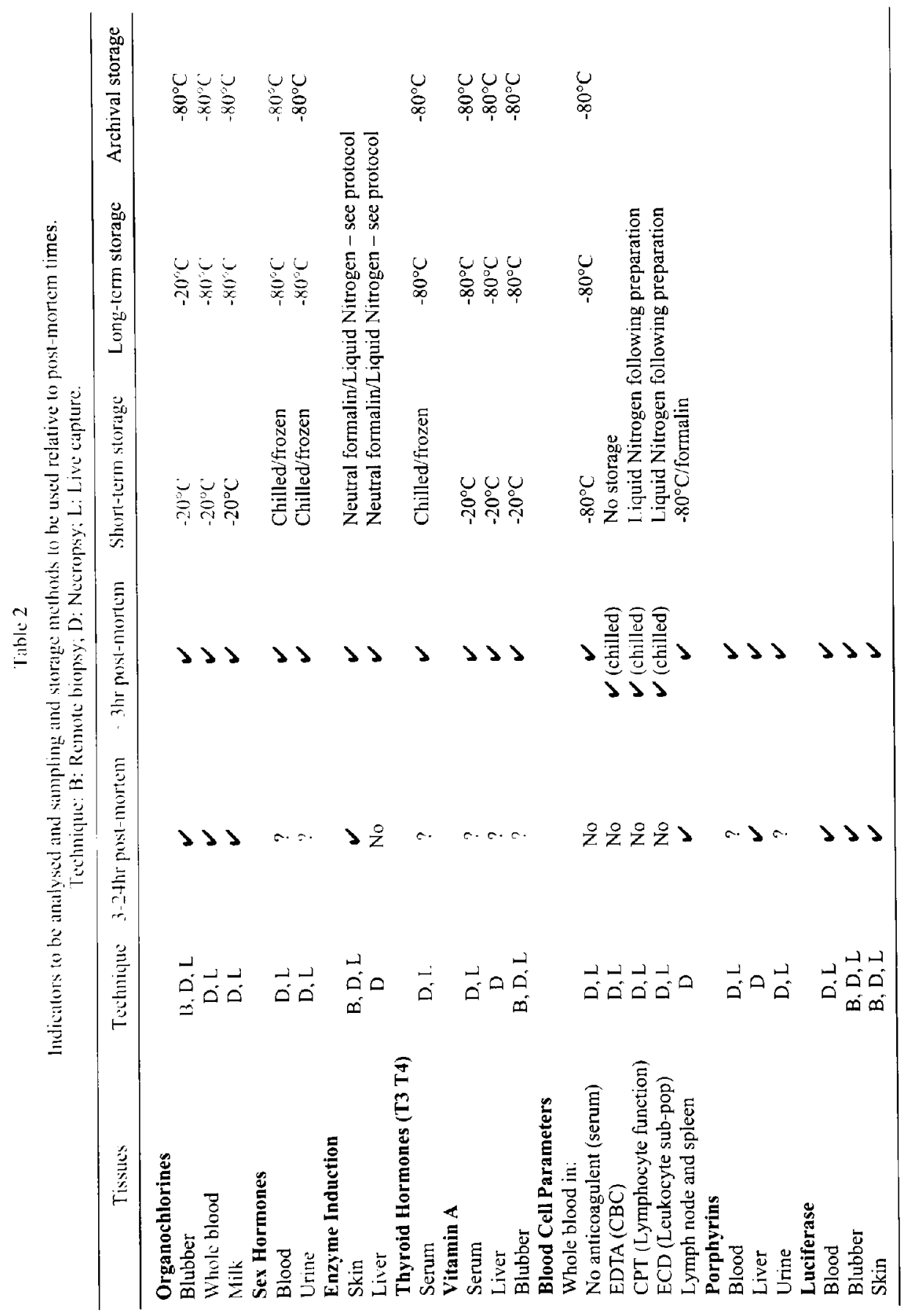




\subsection{Analyses}

\subsubsection{Pollutants and indicators}

The Workshop agreed that in order to minimise sources of error, ideally analyses of each variable would be undertaken by a single laboratory. In practice, it was agreed that this should be ensured at least for each species. The Workshop emphasised the need for only experienced (in marine mammals) and quality assured laboratories to be used. Potential laboratories are listed in Table 3. This list is not intended to be exclusive. Final responsibility for the selection of laboratories should lie with the Steering Group (see Item 8). Appropriate cross calibration should occur where necessary.

\subsubsection{Biological material}

Most standard biological analyses can be carried out by the collecting institution, following a standard protocol to be defined by the Steering Group (see Item 8). However the Workshop made the following observations with respect to certain items.

\subsubsection{AGEING OF TEETH}

The Workshop recommends that at least $20 \%$ of teeth from the various areas are cross-read. The final details of this will be decided by the Steering Group.

\subsubsection{GENETIC DETERMINATION OF SEX/GENETIC PROFILE}

A number of institutes carry out such work, including: the University of Barcelona; Portland State University; NMFS; University of Bangor; University of Aarhus; and the University of Kiel.

\subsubsection{Routine histopathology (formalin-fixed)}

For the bottlenose dolphin studies, this will be applicable to only a few stranded animals. Wells already has an established system for this. However, for the harbour porpoise work, there will be a large number of samples. It was agreed that details for cross-examining slides should be finalised by the Steering Group. This should involve 3-5 workers. Suitable candidates include Wester, Bergmann, Siebert and a number of North American scientists.

\section{ORGANISATION/COORDINATION}

\subsection{Coordinator and steering group}

The Workshop identified a number of outstanding and ongoing items at both the scientific and logistical level that can best be addressed by the appointment of a Steering Group. These items are listed in Table 4. Many, if not all, have funding implications. It was agreed that Reijnders should act as the coordinator of the Steering Group and that the Group should comprise a representative from each sub-project (Wells - bottlenose dolphin, live-capture programme; Aguilar - bottlenose dolphin, biopsy programme; Bjørge - harbour porpoise, bycatch programme; Siebert - technique validation/calibration programme); Donovan (IWC); Rowles; plus a statistician/modeller, a biomarker expert and someone with an overview of cetacean biology, pathology, toxicology and veterinary medicine. It was agreed that the latter three should be determined after this Workshop by the Steering Group. 


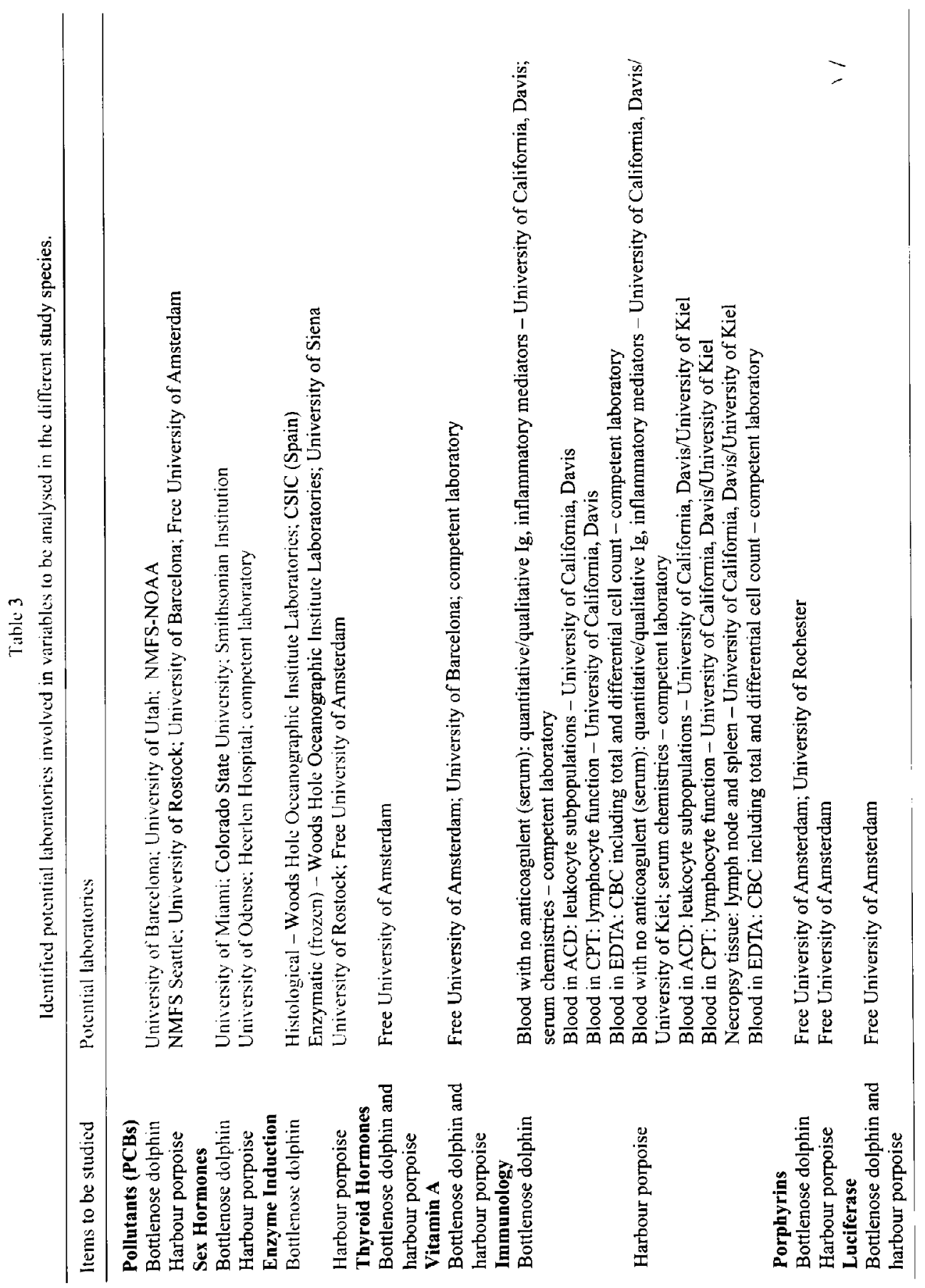


Table 4

Ongoing and outstanding items to be addressed by the Pollution $2000+$ Steering Group.

\begin{tabular}{|c|c|}
\hline Item(s) to be addressed by Stcering Group & When \\
\hline Formulate questions and co-ordinate replies on field logistics & Pre-Grenada \\
\hline $\begin{array}{l}\text { Determine funding requirements, examine implications and priorities, investigate } \\
\text { other sources of funding, accounting }\end{array}$ & Pre- and post- Grenada \\
\hline Establish field protocols* & Late 1999 \\
\hline Logistics of sample handling e.g. shipping (incl. permits); archiving & Throughout \\
\hline $\begin{array}{l}\text { Co-ordinate analysis of sub-projects. review results, synthesis of sub-project data; } \\
\text { review and evaluation and completion of final report; planning for the next phase* }\end{array}$ & Throughout \\
\hline Data storage and availability & Throughout \\
\hline
\end{tabular}

* Organisation of workshops.

\subsection{Timetable}

The Workshop noted that the IWC would not take a decision on funding until June 1999. It is clear therefore, that fieldwork is unlikely to begin until the year 2000. Although the details will be the responsibility of the Steering Group, it is envisaged that at least three Workshops will be required, probably in December 2001, mid-2004 and early 2005, with the aim of presenting a final report to the IWC at its Annual Meeting in 2005.

\subsection{Budget and funding}

It is not possible for the Workshop to develop a precise budget, given the need to obtain further details on the field programme and the implications of this for analyses. It therefore agreed that this task should be completed by the Steering Group, based on the requirements given in the Workshop report and attached as an Annex in time for the Scientific Committee meeting in Grenada in May this year [1999] (see Annex C).

Noting the support for this proposal from ASCOBANS, the Steering Group should also contact this and other relevant groups for possible co-sponsorship. NAMMCO has also been examining issues of pollutants and had been invited to attend this workshop but had been unable to attend. They should also be approached as potential collaborators.

When endorsing the IWC proposal for cetaceans, the ICES Working Group on Marine Mammal Habitats had decided to develop a related project for pinnipeds. They met earlier this month [March 1999] in Copenhagen and formulated such a programme. The Workshop agreed that the Steering Group should explore further the possibility of a joint proposal being submitted to the EU.

Even without the ability to develop a detailed budget, it is clear that the total funding required will be extremely high by IWC standards. This had already been pointed out in the original proposal. The Workshop strongly believes that the POLLUTION 2000+ project represents the fundamental research necessary if the effects of pollutants on cetaceans are to be determined. In addition to central IWC funding, therefore, it urges IWC member governments to consider providing support to this project at the national level.

\subsection{Report and publications}

The Workshop agreed that the final report to the IWC should be completed after a Workshop to review results, probably to be held in early 2005 . Given the leading role taken by the IWC in this programme, the Scientific Committee had agreed that it was appropriate that selected 
resultant papers should be published as an IWC Special Issue. This does not preclude other papers being published elsewhere. This matter should be discussed further, both within the Steering Group and, if appropriate, with other co-sponsors.

\section{ADOPTION OF REPORT}

The Report of the Workshop was adopted at the end of the meeting. However, it was agreed that a detailed budget should be drawn up after the meeting by Aguilar, Donovan and Reijnders based on a questionnaire sent out to the institutes/individuals listed in Table 3 and Item 7.1. Details are given in Annex C.

\section{REFERENCES}

Aguilar, A. and Borrell, A. 1990. Patterns of lipid content and stratification in the blubber of fin whales (Balaenoptera physalus). J. Mammal. 71(4):544-54.

Aguilar, A.. Bjorge, A., Donovan, G. and Reijnders, P. 1998. Proposal to the IWC on furthering the Recommendations of the Pollution Workshop. Rep. int. Whal. Commn 48:425-8.

Aguilar. A., Borrell. A. and Pastor, T. 1999. Biological factors affecting variability of persistent pollutant levels in cetaceans. J. Cetacean Res. Manage. (special issue 1):83-116.

Braham, H.W. 1984. Review of reproduction in the white whale, Delphinapterus leucas, narwhal, Monodon monoceros, and Irrawaddy dolphin, Orcaella brevirostris, with comments on stock assessment. Rep. int. Whal. Commm (special issue) 6:81-9.

Donovan, G.P. and Bjorge, A. 1995. Harbour porpoises in the North Atlantic: edited extract from the Report of the IWC Scientific Committee, Dublin 1995. Rep, int. Whal. Commn (special issue) 16:3-25.

Hohn, A.A. and Lockyer, C. 1995. Report of the Harbour Porpoise Age Determination Workshop, Oslo, 21-23 May 1990. Appendix 3. Protocol for obtaining age estimates from harbour porpoise teeth. Rep. int. Whal. Commn (special issue) 16:494-6.

International Whaling Commission. 1994. Chairman's Report of the Forty-Fifth Annual Meeting, Appendix 12. Resolution on research on the environment and whale stocks. Rep. int. Whal. Commn 44:35.

International Whaling Commission. 1997. Report of the IWC Workshop on Climate Change and Cetaceans. Rep. int. What Commn 47:293-319.

International Whaling Commission. 1998a. Chairman's Report of the Forty-Ninth Annual Meeting. Rep. int. Whal. Commn 48:17-52.

International Whaling Commission. 1998b. Report of the Scientific Committee, Rep. int. Whal. Commn 48:53-127.

International Whaling Commission. 1999. Report of the SOWER 2000 Workshop, March 1999, Edinburgh. I. Cetacean Res. Manage. 2 (Suppl.):In press.

Lockyer, C. 1995. Aspects of the morphology, body fat condition and biology of the harbour porpoise, Phocoena phocoena, in British waters. Rep. int. Whal. Commn (special issue) 16:199-209.

Marine Mammal Commission. 1999. Marine Mammals and Persistent Ocean Contaminants. Proceedings of the Marine Mammal Commission Workstiop, Keystone, Colorado, 12-15 October 1998. 150pp+vii.

Palsboll, P.J., Vader, A., Bakke, I. and El-Gewely, M.R. 1992. Determination of gender in cetaceans by the polymerase chain reaction. Can. J. Zool. 70:2166-70.

Politi. E. 1994. Behavioural sampling. pp. 13-5. In: G. Notarbartolo di Sciara, P.G.H. Evans and E. Politi (eds.) ECS Newsletter. 23. Proceedings of the Workshop 'Methods for the Study of Bottlenose Dolphins in the Wild'. 8th Annual Meeting of the European Cetacean Society. Maison de l'Environment, Montpellier, 3 March 1994. European Cetacean Society.

Read, A.J. 1990. Reproductive seasonality in harbour porpoises, Phocoena phocoena, from the Bay of Fundy. Can. J. Zool. 68(2):284-8.

Reijnders, P.J.H. 1999. Reproductive and developmental effects of endocrine-disrupting chemicals on marine marnmals. pp. 93-100. In: Marine Mammals and Persistant Ocean Contaminants. Proceedings of the Marine Mammal Commission Workshop, 12-15 October 1998, Keystone, Colorado. 150pp.

Reijnders, P.J.H., Donovan, G.P., Aguilar, A. and Bjørge, A. (eds.). 1999. Report of the Workshop on Chemical Pollution and Cetaceans. J. Cetacean Res. Manage. (special issue 1):1-42.

Ronis, M.J., Borlakoglu, J., Walker, C.H., Hanson, T. and Stegeman, J.J. 1989. Expression of orthologues to rat $\mathbf{P}-4$ 50IA1 and IIB 1 in sea-birds from the Irish Sea, 1978-88. Evidence for environmental induction. Mar. Environ. Res. 28:123-30. 
Tanabe, S., Kannan, N., Wakimoto, T. and Tatsukawa, R. 1987. Method for the determination of three toxic non-ortho chlorine substituted coplanar PCBs in environmental samples at part-per-trillion levels. Int. J. Environ. Anal, Chem. 29:199-213.

Urian, K.W., Duffield, D.A., Read, A.J., Wells, R.S. and Shell, E.D. 1996. Seasonality of reproduction in bottlenose dolphins, Tursiops truncatus. J. Mammal. 77(2):394-403.

Wells, R.S. and Scott, M.D. In press. Bottlenose dolphins. In: R. Haebler and A. Hohn (eds.) Factors in Morbidity and Mortality of Dolphins. NOAA Technical Report.

Wells, R.S., Rhinehart, H.L., Sweeney, J., Townsend, F., Casper, D. and Hansen, L..J. 1995. Assessment of the health of bottlenose dolphin populations in Sarasota Bay, Florida, and Matagorda Bay, Texas. Paper presented to the $1 \mathrm{lth}$ Biennial Conference on the Biology of Marine Mammals, 14-18 December, Orlando, Florida. [Available from the author].

Zakharov, V.M. and Yablokov, A., V. 1990. Skull asymmetry in the Baltic grey seal - effects of environmental pollution. Ambio 19(5):266-9. 


\section{Annex A}

\section{List of Participants}

\author{
Alex Aguilar \\ Faculty of Biology \\ University of Barcelona \\ Avinguda Diagonal 645 \\ Barcelona 08071 \\ Spain \\ Tel: +34934021453 or +34934034556 \\ Fax: $+3+934035740$ \\ E-mail: alexa(aporthos.bio.ub.es
}

Amaya Albalat Ribe

Environmental Chemistry Department

CID-CSIC

C/ Jordi Girona 18-26

Barcelona 08034

Spain

Tel: +34934511165

E-mail: aarqum@cid.csic.es

Pierre Beland

St Lawrence National Institute of Ecotoxicology

460 Champ-de-Mars, \#504

Montreal (Que)

H2Y $1 B 4$

Canada

Tel: +1 5144993499

Fax: +1 5149821788

E-mail: belandp@cam.org

Anders Bergman

Contaminant Research Group

Swedish Museum of Natural History

Box 50007

S-104 05 Stockholm

Sweden

Tel: +46851954211

Fax: +46851954256

E-mail:wawa.persson@nrm.se
Asuncion Borrell

Faculty of Biology

University of Barcelona

Avinguda Diagonal 645

Barcelona 08071

Spain

Tel: +34934021453

Fax: +34 934035740

E-mail: assump@porthos.bio.ub.es

Gemma Cantos

Faculty of Biology

University of Barcelona

Avinguda Diagonal 645

Barcelona 08071

Spain

Tel: +34934021453

Fax: +34934035740

E-mail:gcantos@porthos.bio.ub.es

Greg Donovan

International Whaling Commission

The Red House, 135 Station Road

Impington

Cambridge CB4 9NP

UK

Tel: +441223233971

Fax: +44 1223232876

E-mail: greg/WC@compuserve.com

Finn Larsen

Danish Institute For Fisheries Research

Charlottenlund Slot

DK-2920 Charlottenlund

Denmark

Tel: +4533963468

Fax: +4533963333

E-mail:fl@dfu.min.dk 
Clare Last

International Whaling Commission

The Red House, 135 Station Road

Impington

Cambridge CB4 9NP

UK

Tel: +44 1223233971

Fax: +441223232876

E-mail: clast@iwcoffice.org

Michael Moore

Biology Dept. Redfield 2-44, MS 33

Woods Hole Oceanographic Institution

Woods Hole, MA, 02543-1049

USA

Tel: +1 5082893228

Fax: +1 5084572169

E-mail:mmoore@nhoi.edu

Todd O'Hara

Department of Wildlife Management

North Slope Borough

Box 69

Barrow

Alaska 99723

USA

Tel: +19078520350

Fax: +1 9078520351

E-mail:tohara@co.north-slope.ak.us

Cinta Porte-Visa

Environmental Chemistry Dept

CID-CSIC

C/ Jordi Girona 18

Barcelona 08034

Spain

Tel: +34934006175

Fax: +34 932045904

E-mail: cpucam(acidasic.es

Peter Reijnders

Institute for Forestry and Nature Research

PO Box 167

1790 AD Den Burg

The Netherlands

Tel: +31 222369700

Fax: +31 222319235

E-mail:p.j.h.reijnders@ibn.dlo.nl
Teri Rowles

Office of Protected Resources

National Marine Fisheries Service

1315 East West Highway

Silver Spring

MD 20770

USA

Tel: +13017132322

Fax: +1 3017130376

E-mail: teri.rowles@noaa.gov

Ursula Siebert

Forschungs- und Technologie-zentrum

Westkueste

Hafentoern

D-25761 Buesum

Germany

Tel: +494834604280

Fax: +49 48346772

E-mail: usiebertaft-west.uni-kiel.de

Jeff Stott

Laboratory for Marine Mammal

Immunology

School of Veterinary Medicine

Dept. PMI

University of California

Davis, CA 95616

USA

Tel: +l $53075225+3$

E-mail: jlstotr(a ucdavis.edu

Gisli Vikingsson

Marine Research Institute

PO Box 1390

Reykjavik 121

Iceland

Tel: +354 5520240

Fax: +3545623790

E-mail: gisli(ahafro.is 
Randy Wells

c/o Mote Marine Laboratory

1600 Ken Thompson Parkway

Sarasota

Florida 34236

USA

Tel: +19413884441

Fax: $+1941388+223$

E-mail:ruells@mote.or:
Piet Wester

Head Dept. Pathology

National Institute for Public Health and the Environment (RIVM)

PO Box 1

3720 BA Bilthoven

The Netherlands

Tel: +31 302742242

Fax: +31302744437

E-mail:p.wester@rivm.nl 


\title{
Annex B
}

\section{Draft Agenda}

\author{
1. Introduction
}

2. Arrangements for the meeting

3. Objectives of the programme

4. Identification of variables to be measured

4.1 Pollutants

4.2 Indicators

4.3 Biological variables

4.4 Pathology

5. Analytical techniques

5.1 Pollutants

5.2 Indicators

5.3 Biological variables

5.4 Pathology

6. Sampling (by species, area and variable)

6.1 Sample size and composition (age, sex, etc.)

6.2 Collection method (including amount of sample required)

6.3 Short-term storage

6.4 Long-term storage and shipment

7. Responsible laboratories

7.1 Sample collection

7.2 Analyses

8. Organisation/coordination

8.1 Coordinator and Steering Group

8.2 Timetable

8.3 Budget and funding

8.4 Report and publications

9. Adoption of report 


\title{
Annex C
}

\section{POLLUTION 2000+: after Barcelona}

\author{
P.J.H. Reijnders, T. Rowles, G.P. Donovan, T. O’Harı, A. Bjørge, F. Larsen and \\ K-H. KorK
}

\section{INTRODUCTION}

The preceding report of the Workshop addressed the request of the Commission, its Scientific Committee and the SWG on Environmental Concerns (SWGEC) to further develop the research proposal on cetaceans and pollutants, hereafter called Pollution $2000+$. The starting point for the Workshop was established by the SWGEC, Scientific Committee and Commission as given in IWC $(1998 \mathrm{a} ; \mathrm{b})$ in which the measured variables - pollutants and biomarkers (indicators of exposure and/or effects), and the target species, had been identified and agreed upon.

PCBs were chosen as model compounds because of their overwhelming anthropogenic origin, very high concentrations in some cetacean populations, recognised effects upon wildlife and the substantial background information already available on patterns in variation, geographical distribution, tissue kinetics and mechanisms of action. By analysing PCBs it was recognised that from the same samples, for no extra cost, information will be obtained on a series of other organochlorines including DDT, DDE, DDD, dieldrin, endrin, eldrin, heptachlor epoxide, lindane, hexachlorobenzene, chlordanes and mirex.

The biomarkers and other indicators previously agreed upon by the SWGEC, Committee and Commission, were discussed and described in more detail in the reports referred to above. These biomarkers are essentially indicators of possible effects on reproduction, early development, the immune system and general health status related largely, but not exclusively, to PCB-exposure.

With respect to target species, it was agreed in Barcelona that of the four identified species (bottlenose dolphin, harbour porpoise, white whale and Amazon river dolphin), only two species will be examined in this proposal. The possibilities to obtain adequate matching samples (size, type covering a sufficient gradient of pollution), precluded the inclusion of the white whale and the Amazon river dolphin in Pollution 2000+. However, it was also noted that pollutant studies on these species (and indeed others) are important and may be included in future phases of this iterative project. Interested groups are encouraged to undertake such studies. The collection and at least archival of samples from these populations should be encouraged by IWC.

Last year, the Scientific Committee stressed, and this was again clearly stated in Barcelona, that the programme was intended to specifically address the main recommendation of the IWC Pollution Workshop. Researchers were encouraged to address the other recommendations of that Workshop and consider other species and sources of samples. The priorities of the research programme were not meant to imply that other approaches were untenable, but rather, that it was important for the IWC to focus its effort on particularly important questions that would have wide ranging benefits to studies of cause-effect relationships in cetaceans.

As clearly stated in Barcelona: 


\begin{abstract}
'It is important to stress that the development of the IWC programme should not be seen as suggesling that other research on pollutants and cetaceans is not important. The IWC programme should be seen as a 'core' programme to address some fundamental questions. Its value is immeasurably enhanced by cooperation with existing programmes and as a context for the development of new programmes. The IWC should cooperate with other bodies in a coordinating role.'
\end{abstract}

Focusing on PCBs and these two species increases the power of the experimental design (i.e. increased sample size within a species) to better determine if the proposed biomarkers will be useful in discriminating the populations at greatest risk to organochlorine effects. It is also intended to produce a model for studies of other contaminants in other species and areas, by bringing together biologists, (toxico) pathologists and others in a multidisciplinary collaborative programme.

It is also worthwhile reiterating that samples will be archived for further analyses outside the core programme following the guidelines listed in table 2 of the Barcelona Workshop report. The Workshop had also encouraged auxiliary projects to be taken up by national groups and other institutions. For example, the assessment of new or recently found compounds in cetaceans, such as organotins and polybrominated biphenyls, is, of course, of relevance to cetaceans.

\title{
DEVELOPING A BUDGET
}

\section{In Barcelona it was noted that it}

'was not possible for the Workshop to develop a precise budget, given the need to obtain further details on the field programme and the implications of this for analyses. It therefore agreed that this task should be completed by the Steering Group, based on the requirements given in the Workshop report and attached as an Annex in time for the Scientific Committee meeting in Grenada in May this year."

In practice, this required sending out questionnaires to the identified field research contacts and the potential laboratories identified in the Barcelona Workshop report. Final replies to these questionnaires were not received until the start of the meeting. It has therefore not been possible to circulate and receive comments back from the full Steering Group identified in the Barcelona Workshop report - thus only the above-named authors are responsible for this document.

\section{ESTIMATED COSTS}

The questionnaire asked all potential institutes to provide estimates of the costs involved in their participation. An overview of the responses is given in Appendix 2. The Workshop had recommended that it should be the decision of the Steering Group to decide on the final institutions, with the primary consideration being given to quality assurance followed by cost. The total budget for all of the analyses identified in the Barcelona Workshop report is ca $£ 1,300,000$. Thus the prophecy from the Bergen Workshop and IWC (1998) has been fulfilled - this type of research programme is very expensive.

IWC (1998, p.427) had noted that the project would be a very large, co-operative programme - one that the Commission alone would be unable to fund. The level of support already expressed for this proposal is extremely encouraging. The programme as outlined in IWC (1998) was strongly endorsed by ASCOBANS at its Meeting of Parties. The recent Advisory Committee meeting of ASCOBANS also endorsed the Barcelona Workshop report on the basis of the summary prepared by Reijnders (the Committee's rules meant that the written report could not be submitted as a document to that meeting). IWC (1998) was also endorsed by ICES and used by them to develop a similar programme for pinnipeds. 
Although it has not been possible to calculate the exact value of the 'in-kind' funding offered by the cooperating institutions, even a crude estimate reveals that over $£ 200,000$ is being offered and probably considerably more. Further potential funding sources include: the European Commission, the joint USA-EU programme; the Nordic Council of Ministers; and certain Fishermen's Associations. It is to be hoped that IWC member nations may also offer direct or indirect funding in addition to any core IWC funding. Similarly, one might hope that various non-governmental organisations might be prepared to contribute.

It was foreseen that one of the tasks of the coordinator of POLLUTION 2000+ would be to follow up on these and other sources of funding. This is an important part of the initial segment of the programme.

\section{REFINING THE PROPOSAL}

Based on the Barcelona Workshop report the following two short-term objectives were identified for POLLUTION 2000+:

(a) to select and examine a number of biomarkers of exposure to and/or effect of PCBs and Iry to determine whether a predictive and quantitative relationship with PCB levels in certain tissues exists;

(b) to validate/calibrate sampling and analytical techniques to address such questions for cetaceans, specifically:

(i) determination of changes in concentrations of variables with post-mortem times;

(ii) examination of relationships between concentrations of variables obtained from biopsy sampling with those of concentrations in other tissues that can only be obtained from fresh carcasses.

Given these objectives and the levels of resources and effort necessary to examine them, we propose that the work be divided into two phases; information from Phase 1 is important in providing the calibration/validation tools necessary to better focus and design Phase 2 . The importance of calibration studies for the interpretation of pollutant-related data has been stressed both in Bergen and subsequently. Data from Phase 1 will provide information not only essential for completing Phase 2 of POLLUTION 2000+ but also of fundamental importance to many research programmes examining issues of chemical pollutants and cetaceans. Thus, Phase 1 concentrates largely on objective (b) above and comprises two sub-projects: (1) effect of post-mortem time; and (2) relationship between information obtained from biopsy samples with that obtained from live-captured animals or carcasses (either from bycaught or freshly stranded animals).

Phase 1 data are to be analysed before embarking on Phase 2. The need for a Workshop or Workshops to evaluate data from the project is clearly stated in the Barcelona Workshop report. This will inevitably result in a revised programme to be presented to the Committee and the Commission. However, it would be misleading if the likely funding levels for Phase 2 of the programme were not also presented to the Commission.

\section{Effect of post-mortem time}

Changes in levels of contaminants and indicators of exposure are known to occur after death due to the inevitable physiological changes and breakdown of tissue (e.g. see Barcelona Workshop report). It is essential that these changes are quantified to determine the effect of post-mortem time on levels in the various tissues if the implications of measured levels of these in animals whose time to death is uncertain are to be correctly interpreted with respect to concentrations in the living animal. 


\section{Information from biopsy samples}

In order to look at potential effects of pollutants at the population level (the ultimate aim of the research programme; Aguilar et al., 1998), it is necessary to try and develop techniques that will allow collection of data from large numbers of free-living animals. One such method is obtaining biopsy-samples. However, to interpret the results from such samples it is essential to know how those levels obtained via such techniques (skin/blubber) relate to other tissues which are in practice obtained via live-capture (blood) and necropsies (e.g. liver, kidney and muscle). In this way we will acquire more insight into how far it might be possible to relate some indicators of exposure found through biopsy techniques to indicators and associated pathological findings obtained via necropsies.

It is therefore extremely important that such 'calibration' studies are undertaken before embarking on Phase 2 involving bycaught or freshly stranded animals. It should be possible to address both questions via the same sampling regime. The post-mortem experiment could be carried out on a selected subset of the biopsy calibration experiment animals. The absence of a suitable source of fresh carcasses of bottlenose dolphins means that the calibration experiments will be carried out on harbour porpoises. The choice of sampling area or areas needs to be decided by the Steering Group.

It can be seen that Phase 1 includes the field research component as well as analyses of the bottlenose dolphin sub-project in the Sarasota Bay area, and the field research component of the bottlenose dolphin sub-project in Mauritania, Bahamas and the Mediterranean, but, that only the PCB analyses are being undertaken as part of Phase 1 . The rationale for the latter is that (a) it takes advantage of existing field work; and (b) it will enable selection of a single 'unpolluted' area on which to focus the Phase 2 segment. The remaining indicator analyses from the samples collected in Phase 1 will be undertaken as part of Phase 2. depending upon the findings of Phase 1.

\section{REFERENCES}

Aguilar, A., Bjørge, A., Donovan, G. and Reijnders, P. 1998. Proposal to the IWC on furthering the Recommendations of the Pollution Workshop. Rep. int. Whal. Commn 48:425-8.

International Whaling Commission. 1998a. Chairman's Report of the Forty-Ninth Annual Meeting. Rep. int. Whal. Commn 48:17-52.

International Whaling Commission. 1998b. Report of the Scientific Committee. Rep. int. Hhal. Commn 48:53-127.

\section{Appendix 1}

\section{BRIEF OUTLINE OF THE EXPERIMENTAL DESIGN OF THE CALIBRATION SUB-PROJECT}

The importance of age and sex in interpreting tissue levels of contaminants is well known. Therefore any such study must consider at least the following categories if practical: immature males; adult males; immature females; adult females - pregnant; adult females resting; adult females - lactating.

For the post-mortem sub-project, the calibration exercise must cover the likely range of time to death for bycaught animals under usual fishing operations. It is suggested that for each individual, samples are taken for the following times to death: $0,3,6,12,18$ and $24 \mathrm{hrs}$. Attention should be given to storing the carcass in a manner likely to most closely resemble the conditions of a bycaught animal left in the nets. It is important that animals that are known to have very recently $(<15 \mathrm{mins})$ died are used. The $0 \mathrm{hr}$ measurements are the equivalent of a biopsy sample. For Phase 1, five animals in each category should be 
examined. Whether further analyses are required for Phase 2 will be determined after the results from Phase 1 become available.

A full autopsy must be undertaken after the last samples have been taken and where possible, the variables outlined in Table 1 must be measured.

Table 1

Variables to be measured.

\begin{tabular}{ll}
\hline Variable & Tissue \\
\hline PCBs & Blubber \\
& Blood \\
& Milk \\
Porphyrines & Blood \\
& Liver \\
& Urine \\
Immune system & Whole blood (see Table 2) \\
Thyroid hormones & Serum \\
P450 & Skin \\
& Liver \\
Luciferase & Blood \\
& Blubber \\
Sex hormones & Skin \\
& Blood \\
Vitamin A & Urine \\
& Blubber \\
& Blood \\
& Liver \\
\hline
\end{tabular}

Appendix 2

BUDGET FOR PHASE 1 OF POLLUTION 2000+

\section{Administration}

This is an extremely important item if the project is to succeed. $£ 20,000$ is required.

\section{Post-mortem calibration study - harbour porpoises - five animals in each class}

(1) Due to the ability to sample blood, it is assumed that analyses will only be carried out for $0,3,6$ and 24 hrs (i.e during necropsy);

(2) In order to obtain sufficient $0 \mathrm{hr}$ specimens for the various age-sex classes, it is necessary to sample more widely. For those animals sampled that are not freshly dead, tissue will be archived for analysis under Phase 2 of the programme. The number of sampled animals necessary to obtain sufficient animals in each class is difficult to determine, but for purposes of the budget it is assumed that about 120 animals will be sufficient. Sampling may occur in Iceland, Norway, Denmark, USA and Germany. 


\begin{tabular}{lllrr}
\hline Samples & Variable & Tissuc & $\begin{array}{c}\text { Cost per } \\
\text { sample (£) }\end{array}$ & Total (f) \\
\hline 180 & PCBs & Blubber & 105 & 18,900 \\
120 & & Blood & 105 & 12,600 \\
180 & Vitamin A & Blubber & 85 & 15,300 \\
180 & & Liver & 85 & 15,300 \\
180 & & Blood & 85 & 10,200 \\
120 & Porphyrines & Blood & 65 & 7,800 \\
180 & & Liver & 65 & 11,700 \\
180 & & Urine & 65 & 11,700 \\
120 & Immune system & Wholc blood & 256 & 30,762 \\
180 & Thyroid hormones & Serum & 8 & 1,435 \\
180 & P450 & Skin & 0 & 0 \\
180 & & Liver & 66 & 11,932 \\
120 & Luciferase & Blood & 216 & 25,888 \\
180 & & Blubber & 232 & 41,819 \\
180 & & Skin & 332 & 59,741 \\
120 & Sex hormoncs & Blood & 10 & 1,200 \\
Sub-total & & & & 276,278 \\
Field costs & & & 25,000 \\
Sub-project cost & & & $\mathbf{3 0 1 , 2 7 8}$ \\
\hline
\end{tabular}

3. Bottlenose dolphin sub-project:

\begin{tabular}{|c|c|c|c|c|}
\hline Sample size & $\begin{array}{l}\text { Field costs } \\
\text { (f) }\end{array}$ & Analysis & Tissue & Total $(\mathfrak{f})$ \\
\hline \multicolumn{5}{|l|}{ Mauritania } \\
\hline 15 & 12,900 & PCBs & Blubber & 1.575 \\
\hline \multicolumn{5}{|l|}{ Bahamas } \\
\hline 15 & 5,000 & PCBs & Blubber & 1,575 \\
\hline \multicolumn{5}{|l|}{ Mediterranean } \\
\hline 15 & 10,600 & PCBs & Blubber & 1,575 \\
\hline Sub-total & & & & 33.225 \\
\hline \multicolumn{5}{|l|}{ Sarasota Bay } \\
\hline 30 & 6,000 & PCBs & Blubber & 3,150 \\
\hline 30 & & & Blood & 3,150 \\
\hline 10 & & & Milk & 1,050 \\
\hline 30 & & Hormones & Blood & 300 \\
\hline 30 & & Enzyme induction & Skin & 1,071 \\
\hline 30 & & Porphyrines & Blood & 1,950 \\
\hline 30 & & & Urine & 1,950 \\
\hline 30 & & Immune system & Whole blood & 7,691 \\
\hline 30 & & Thyroid hormones & Serum & 239 \\
\hline 30 & & Luciferase & Blood & 6,472 \\
\hline 30 & & & Blubber & 6,970 \\
\hline 30 & & & Skin & 9,957 \\
\hline 30 & & Vitamin A & Scrum & 2,550 \\
\hline 30 & & & Blubber & 2,550 \\
\hline Sub-total & & & & 55,050 \\
\hline \multicolumn{4}{|c|}{ Sub-project cost } & 88,275 \\
\hline
\end{tabular}

